\title{
Os percursos escolares de uma criança com mielomeningocele e insuficiência renal crônica
}

\author{
The school pathways of a child with myelomeningocel and chronic \\ renal failure
}

\author{
1 Rosangela Aparecida Souza bioped.rosangela@gmail.com \\ 1 Lúcia Maria Santos Tinós Itinos@ffclrp.usp.br \\ 1 Sheila Maria Mazer-Gonçalves sheilamazer@ffclrp.usp.br
}

1 Faculdade de Filosofia Ciências e Letras de Ribeirão Preto - FFCLRP/USP. Ribeirão Preto, São Paulo, Brasil.

\begin{abstract}
Resumo
Pensar no direito à Educação é compreender crianças e adolescentes com doença crônica que, em seu tratamento, demandam horas semanais no ambiente hospitalar no decorrer de suas vidas escolares, poderão apresentar, em algum momento, necessidades educacionais específicas. Buscou-se compreender a trajetória escolar de uma adolescente com mielomeningocele e insuficiência renal crônica, delineando os percursos escolares, na escola e no hospital. Neste estudo fenomenológico, os dados foram coletados por meio de entrevistas semiestrururada e registro em caderno de campo. As participantes foram uma adolescente em tratamento hemodiálitico e sua progenitora. Esta pesquisa permitiu identificar necessidades educacionais específicas da adolescente e o fazer pedagógico, em um centro de hemodiálise. As condições objetivas da doença crônica configuraram deficiências que foram diagnosticadas e construídas, pela equipe de saúde, mãe e adolescente, ao longo de seu percurso escolar, evidenciando dificuldades e entraves nesse processo. Por outro lado, o olhar durante os atendimentos pedagógico-escolares descortinou novos caminhos que poderiam descontruir a autoimagem da deficiência e da incapacidade de aprender. Pode-se inferir que a doença crônica e seu tratamento não inviabiliza a vida escolar, desde que haja as condições educacionais para criar elos entre o hospital e a escolarização. Destaca-se a atuação pedagógica em centros de hemodiálise e a necessidades de mais pesquisas na área.
\end{abstract}

\section{Palavras-chave}

Mielomeningocele. Insuficiência renal crônica. Educação inclusiva e necessidades especiais.

\begin{abstract}
To think about the right to education is to understand that chronically ill children and adolescents, who in their treatment demand weekly hours in the hospital environment during their school lives, may at some point have specific educational needs. We sought to understand the school trajectory of an adolescent with myelomeningocele and chronic renal insufficiency delineating the school paths, in the school and in the hospital. In this phenomenological study the data were collected through interviews and recorded in a field notebook. The participants were a teenager on hemodialysis and her mother. This research allowed to identify specific educational needs of the adolescent and the pedagogical doing, in a hemodialysis center. The objective conditions of the chronic disease were deficiencies that were diagnosed and constructed by the health team, mother and adolescent, during their school career, evidencing difficulties and obstacles in this process. On the other hand, the look during the pedagogical-school attendances revealed new ways that could deconstruct the self-image of the deficiency and the inability to learn. It can be inferred that the chronic disease and its treatment does not make school life unfeasible, since there are educational conditions to create links between the hospital and schooling. It is worth noting the pedagogical performance in hemodialysis centers and the need for more research in the area.
\end{abstract}

\section{Keywords}

Myelomeningocele. Chronic renal failure. Inclusive education and special needs.

\section{Como você deve citar?}

SOUZA, Rosangela Aparecida; TINÓS, Lúcia Maria Santos; MAZER-GONÇALVES, Sheila Maria. Os percursos escolares de uma criança com mielomeningocele e insuficiência renal crônica. Cadernos UniFOA, Volta Redonda, n. 37, p. 93-xx, ago. 2018. 


\section{INTRODUÇÃO}

O desejo de uma sociedade mais justa e inclusiva nasce da necessidade de se discutir e eliminar qualquer forma de discriminação em favor da igualdade de direitos; dentre eles, o direito à educação. A Constituição Federativa do Brasil (BRASIL, 1988) prevê como dever do Estado e da família promover e incentivar a todas as crianças um pleno desenvolvimento e, assim, seu preparo para o exercício da cidadania e a qualificação para o trabalho. Além disso, existem ainda leis que regulamentam e complementam o direito à Educação, como o Estatuto da Criança e do Adolescente - ECA (BRASIL, 1990) e a Lei de Diretrizes e Bases da Educação Nacional - LDBEN (BRASIL, 1996).

Nesse sentido, é direito de toda criança e adolescente ter igualdade de condições para o acesso e permanência na escola. Para tal, pode-se afirmar que, no Brasil, as discussões acerca das políticas de educação inclusiva ${ }^{2}$ vêm ganhando espaços. A Lei de Diretrizes e Bases da Educação Nacional LDBEN 9.394/96-(BRASIL, 1996), o Plano Nacional de Educação - PNE (BRASIL, 1997) e Documento Subsidiário à Política de Inclusão (BRASIL, 2005), entre outros, são instrumentos que tentam garantir e viabilizar os rumos que a Educação deve tomar e, assim, criar condições de efetivação de direitos.

Assim, deve-se pensar em todas as crianças e adolescentes na efetivação do direito à educação, bem como na diversidade e nas singularidades do ser humano. Diante desse pressuposto, é importante ponderar a existência das características peculiares de cada um (condições sociais, étnico-raciais, culturais, físicas e biológicas) e, por isso, a necessidade de uma estrutura facilitadora para seu acesso e permanência, não só no ambiente escolar, como laboral e no conjunto social (AMARAL, 1994; BIANCHETTI, 2002).

Nessa perspectiva, pensar no direito à Educação é considerar também crianças e adolescentes que possuem enfermidades que podem ser hospitalizados ou fazer uso de procedimentos médicos e terapêuticos que demandam muitas horas semanais no ambiente hospitalar e que, no decorrer de suas vidas escolares e de todo processo de escolarização, poderão apresentar, em algum momento, necessidades educacionais específicas (MAZER-GONÇALVES, 2013). Essas especificidades, para alguns autores da Educação Especial (ASSIS, 2009; FONSECA, 2003; GONZALEZ; GONZALEZ, 2007), caracterizam crianças e adolescentes enfermos como público que requer um olhar especializado para suas necessidades educacionais.

Para essa situação, existem no Brasil, os documentos legais que garantem o direito aos atendimentos pedagógico-escolares de crianças e adolescentes que se encontram hospitalizados (BRASIL, 1994; BRASIL, 2001; BRASIL, 2002). Contudo, sabe-se que esse serviço, da Educação Especial, ainda não se encontra estruturado, em termos de atendimento, e encontra-se de forma tímida e dispersa pelo país (ARAÚJO, 2017).

Para além dessa discussão, as especificidades de algumas doenças podem delimitar a oportunidade escolar, seja no hospital (clínicas, setores e especialidades) ou na escola. Um exemplo dessa situação refere-se à mielomeningocele ( $\mathrm{MMC}$ ), que é a forma mais grave presente na anomalia conhecida como espinha bífida, causada por defeitos do fechamento do tubo neural embrionário nas primeiras semanas da embriogênese, formando um saco visível no dorso da criança nas regiões lombares, tóraco-lombares ou lombossacrais.

2 Neste artigo, o principio de Educação Inclusiva assume como princípio a Declaração de Salamanca (1990) e Rodrigues (2006), que defendem o direito a uma Educação de qualidade para todos. 
A etiologia da doença é multifatorial e estudos associam a ocorrência da espinha bífida a fatores correlacionados às baixas condições socioeconômicas (FERNANDES, 2003). Os prejuízos neurológicos dependerão da alteração funcional da medula espinhal, quanto mais craniais nos segmentos medulares, maiores serão os prejuízos neurológicos. Portanto, a altura da lesão definirá a gravidade dos problemas, quanto à mobilidade, disfunção intestinal, disfunção urinária, hidrocefalia, deformidades musculoesqueléticas, úlceras de pressão, epilepsia e déficit cognitivo (BIZZI, 2012).

Quanto ao sistema urinário, podem estar presentes, na maioria dos casos, as infecções urinárias recorrentes, tendo como complicação grave o comprometimento renal, levando a uma possível insuficiência renal crônica (IRC) (YUNGE, 1987). A insuficiência renal crônica caracteriza-se em outra doença considerada como problema de saúde pública que possui vários estágios com rigoroso controle da dieta e medicamentos, além de terapia renal substitutiva (hemodiálise ou diálise peritoneal) (BRASIL, 2012). A hidrocefalia está presente em $90 \%$ dos casos de mielomeningocele e é caracterizada por acúmulo de líquido cefalorraquidiano dentro da cavidade craniana (JUCA, 2002). Inegavelmente, os fatores acima mencionados interferem no cotidiano dos indivíduos com essas anomalias, pois exigem inúmeras especialidades médico-hospitalares, além de acompanhamentos e tratamentos constantes.

Existem, na literatura da Pedagogia Hospitalar, campo teórico-prático da Educação Especial (ASSIS, 2009; FONSECA, 2003; MAZER-GONÇALVES, 2013), alguns estudos sobre a importância do atendimento pedagógico-escolar em hospitais para crianças e adolescentes com doença crônica que demonstram que o desenvolvimento escolar sofre interferências, devido às adaptações que são necessárias na rotina diária, em função da doença e do tratamento, acarretando o afastamento da vida escolar (SILVA, COLLET, SILVA E MOURA, 2010).

Assim, pensando no direito à Educação, para todos, e à diversidade de demandas educacionais de uma criança com Mielomeningocele e Insuficiência Renal Crônica, surgiu a necessidade de se conhecer como acontece (ou não) a trajetória escolar dessas crianças e adolescentes.

\section{OBJETIVO}

Compreender a trajetória escolar de uma adolescente com mielomeningocele e insuficiência renal crônica, delineando os percursos escolares, na escola e no hospital.

\section{METODOLOGIA}

A escolha de uma determinada metodologia relaciona-se com a maneira de olhar o mundo, olhar o homem e suas relações (BIANCHETTI, 2001). Assim, a pesquisa de cunho qualitativo vem ao encontro do objetivo deste estudo. Nesse processo, buscou-se respaldo em estudos pautados pelo entendimento fenomenológico que, de acordo com Silva (1987, p.45), "representa uma postura frente ao outro, frente ao ser, para a compreensão do que se revela, na intenção de compreender e interpretar o fenômeno em questão como este se dá a ver.".

Assim, cada sujeito participante, com suas peculiaridades, seu olhar, suas histórias, vai delineando identidades singulares que podem desvelar o fenômeno estudado: os diferentes processos de escolarização que uma criança com meningomielocele e insuficiência renal crônica vem vivenciando. Essa opção entende que as trajetórias reconstruídas desvelam fenômenos (condições e situações) singulares que são merecedoras de um olhar mais apurado, na tentativa de se conhecer os serviços 
que a compõem, essa trajetória, ao mesmo tempo em que colocar seus atores como centro dessa realidade, dando oportunidade de escutá-los (TINÓS, 2010).

Ressalta-se que este artigo é fruto do desdobramento de um projeto maior intitulado Pedagogia Hospitalar no Setor de Hemodiálise Infantil, desenvolvido pelo Grupo de Estudos e Pesquisas em Pedagogia Hospitalar (GEPPH ${ }^{3}$ ), avaliando o atendimento pedagógico-hospitalar que ocorreu entre 2013 a 2015, submetido e aprovado pelo CEP/CONEP, cujo o CAAE é 15749613.5.0000.5407.

\section{SELEÇÃO DOS PARTICIPANTES}

A seleção dos participantes deste trabalho baseou-se nos seguintes critérios: paciente em processo de terapia renal substitutiva (hemodiálise), devido à insuficiência renal crônica, advindo de complicações da condição de mielomeningocele (MMC), que estivesse em processo de escolarização regular, pela indicação e solicitação do Setor de Nefrologia, seção de Hemodiálise de um Hospital Terciário, do interior do estado de São Paulo. Salienta-se que, no ano de 2014, iniciou-se um trabalho de atenção pedagógica nesse setor, por meio do projeto acima referido e, assim, foi constatado, no inicio desta pesquisa, que somente uma criança preenchia os requisitos acima citados. Tratou-se de uma adolescente nascida em 2003, que, no período da coleta de dados, tinha 13 anos e estava cursando o sexto ano do Ensino Fundamental, no período vespertino, em uma escola pública municipal, com atraso escolar significante e muito relutante à aprendizagem.

\section{PROCEDIMENTOS PARA A ANÁLISE DE DADOS}

Após as aprovações e consentimentos da responsável (mãe) e da adolescente, participantes desta pesquisa, iniciamos as entrevistas no primeiro bimestre de 2016, momento em que ambas responderam, de forma isolada e voluntariamente, aos questionamentos, como parte central do desenvolvimento do estudo fenomenológico proposto. Um roteiro de entrevista semiestruturado foi utilizado, primeiramente com perguntas abertas sobre o conhecimento da doença, as dificuldades enfrentadas, lembranças da fase inicial, histórias vivenciadas ou contadas (pelos familiares e equipes hospitalares). À medida que iam sendo respondidas, eram formuladas novas questões com maior ênfase na vivência escolar e social fora do ambiente hospitalar (MARTINS; BICUDO, 2005).

Houve permissão das participantes para que as entrevistas fossem gravadas e transcritas na íntegra, tendo-se o cuidado de preservar em sigilo os dados pessoais dos entrevistados e dos estabelecimentos escolares frequentados pela adolescente pesquisada. Também, as observações e registros, que foram realizados no decorrer do atendimento pedagógico-escolar desenvolvido na pesquisa "Pedagogia Hospitalar no Setor de Hemodiálise Infantil avaliando o atendimento pedagógico-hospitalar", foram levados em consideração.

Assim, as descrições e interpretações foram utilizadas para entender como o fenômeno, nesse caso, a trajetória escolar de uma adolescente com mielomeningocele em tratamento hemodialítico, vem acontecendo, para contextualizar os desafios e/ou dificuldades vivenciadas. Para desvelamentos dos dados coletados, os registros e as entrevistas foram transcritos e foi feita uma primeira leitura atentiva do material descritivo (MARTINS; BICUDO, 2005).

3 O Grupo de Estudos e Pesquisas em Pedagogia Hospitalar é formado por educadoras e alunos do curso de Pedagogia do Departamento de Educação, Informação e Comunicação (DEDIC) da Faculdade de Filosofia, Ciências e Letras de Ribeirão Preto, da Universidade de São Paulo (FFCLRP/USP). 


\section{RESULTADOS}

Logo nas primeiras leituras dos dados e nas observações realizadas, por meio dos encontros e atividades do GEPPH, foi possível iniciar uma compreensão sobre a trajetória escolar dessa adolescente em tratamento hemodialítico.

A adolescente participante é uma aluna do sexto ano do Ensino Fundamental, nascida no ano de 2003, que passou a maior parte de sua infância no ambiente hospitalar, pois recebeu o diagnóstico de mielomeningocele logo após o nascimento. Para a preservação das identidades, nos referiremos à adolescente nos relatos como JFER e a sua progenitora como M.

Sobre a mielomeningocele, JFER reproduz com riqueza de detalhes histórias contadas pela mãe sobre o longo período passado na Unidade de Terapia Intensiva (UTI) do Hospital, logo nas primeiras semanas de vida, quando foi necessária uma intervenção cirúrgica de colocação da válvula para o controle do excesso de líquido cefalorraquidiano, que lhe causava hidrocefalia desde o nascimento. Segundo relato da progenitora $\mathrm{M}$, a correção medular da $\mathrm{MMC}$ ocorreu por intervenção cirúrgica neonatal após o nascimento de JFER e a introdução da válvula foi realizada aos dez dias de vida.

Várias foram as privações desde então, sempre em decorrência da condição da doença e isso está presente nas queixas de JFER relatadas durante as entrevistas. Referindo-se a todas as argumentações ouvidas em consultas, por diferentes profissionais da área de saúde sobre sua doença, a adolescente enfatiza que foi dito que ela teria dificuldades no aprendizado e que muito dificilmente conseguiria aprender como as crianças "normais".

É que eu nasci com uma deficiência que ela atrapalha um pouco o aprendizado... É hidrocefalia mielomeningocele, ela vai pela cabeça, é que tem uma líquida na cabeça, atrapalha muito, então eu não consigo guardar. E, é por causa disso. Especialistas já falaram isso. Eu acho assim, é isso e mais nada (irritadiça). Eu vou aprender a ler e escrever mais lentamente. (JFER)

Queixando-se também sobre o afastamento de atividades sociais, principalmente as atividades escolares, JFER relata que a adaptação primária ao ambiente escolar foi traumática, visto que se lembra de ter chorado bastante ao ser deixada na creche perto de sua casa, aos dois anos de idade.

Ah, eu tinha dois, eu chorei bastante. Então, assim, minha mãe poderia me deixar na creche para sair prá trabaIhar e eu não queria ficar e aí eles: "Não, ela tem que se adaptar. Então desde pequena que eu vou prá escola. $\mathrm{E}$ foi assim. (JFER)

Ao perguntar se ficou por muito tempo chorando e sobre os amigos na creche, a adolescente relatou:

Ah minha mãe ficou lá comigo... (pensativa) Ah, amigos, tipo... Não amigos desta forma..., é assim amigos verdadeiros... Que estou com eles até hoje. Então, assim... Eles me dá bastante apoio... (JFER)

Percebe-se que as interações com as outras crianças na creche deixaram recordações importantes, marcando o início da socialização no ambiente escolar. Além disso, a adolescente prevê possibilidades de crescimento pessoal na escola regular e relata:

Fui pra escola normal, EMEl (...) - Ah eu era pequenininha ainda, era um pitoco. Ali no (...) minha vida começou... eu vi isso, eu vi tudo isso. - Eu vi minha vida, eu vi o que eu ia passar...eu vi o que eu ia aprender, o que eu não ia, eu vi o que a vida ia me ensinar... Assim... a escola ela não só te ensina mas como ela te ajuda a te preparar para a sua vida lá fora, e aí eu aprendi muitas coisas com isso, aprendi lidar com a minha vida. (JFER) 
Segundo a progenitora, JFER começou a frequentar um Centro Municipal de Educação Infantil CEMEl, aos 3 anos de idade, no "Prezinho".

Ela gostava bastante de ir, mas aí interrompia porque ela ficava muito internada com infecção. Depois foi prá uma Escola Estadual, ela foi prá (...) e ficou no (...) 4 anos na classe especial, no período da manhã. É porque ela não tinha desenvolvimento nas outras salas. E aí tinha essa classe especial. Classe especial assim, porque era com menos aluno e a professora tinha mais tempo para dar atenção para eles, aí depois acabou, aí foi prá sala regular normal. (M)

Relata também que JFER frequentou a classe especial na escola regular por quatro anos, antes de iniciar as seções de hemodiálise. Ao ser interrogada sobre a periodicidade dessa frequência, $M$ respondeu:

Então ela frequentava bastante dias, só quando internava que ela não ia para a escola. (M)

Quanto às atividades escolares em casa ou na Classe Hospitalar ${ }^{4}$ nos períodos de internação, respondeu:

Não, ela nunca gostou. Até aqui quando ela fica internada, na classe hospitalar ela não vai. (M)

JFER relata que não gostava de frequentar a Classe Hospitalar no período de internação, pois, as vezes em que isso ocorreu, estava muito indisposta e doente para participar das "chatices de escola". Em relação aos atendimentos pedagógico-escolares no setor de hemodiálise, promovidos pelo projeto supracitado (TINÓS, MAZER-GONÇALVES, FRANCO; SOUZA, 2017), JFER sempre se esquivava, no início dos atendimentos, das atividades, dizendo que "hospital não é escola, não vou fazer atividade nenhuma", logo após cobria a cabeça em protesto.

Assim, no decorrer dos atendimentos pedagógico-escolares, ao disponibilizar materiais para as outras crianças do setor de hemodiálise, sempre buscou-se oferecer para JFER e, em uma dessas ofertas de atividades, percebemos o interesse da mesma pelas artes, em especial a pinturas sobre tela. Conforme o interesse foi crescendo, percebeu-se que JFER, apesar de ter frequentado a escola regular e estar matriculada no sexto ano, não conseguia escrever seu próprio nome e sentia-se envergonhada pela incapacidade, o que a tornava arredia, dizendo que seu interesse girava somente na atividade de pintar as telas.

No decorrer das atividades e com o apoio pedagógico orientado, pode-se, aos poucos, afastar a falsa consciência de incapacidade de aprendizagem da escrita e leitura que JFER alimentava.

Sim, eu acredito que sim porque se eu aprendi a pintar eu vou aprender escrever e a ler. (JFER)

JFER também relaciona seu atraso escolar ao fato de possuir uma "deficiência" capaz de provocar dificuldades na compreensão e memorização das letras. Percebeu-se que há uma contradição entre o que foi definido como deficiência e a resposta de aprendizagem, quando o apoio pedagógico foi sendo conduzido de forma atraente e periódica para ela durante o tratamento hemodialítico.

Assim, o fato de afirmar a uma criança que ela terá dificuldades de aprendizagem no futuro poderá favorecer o afloramento dessas dificuldades, devido às barreiras que vão surgindo no decorrer da trajetória escolar, pois como indica Omote (1996),

4 No hospital, onde a pesquisa foi desenvolvida, existem Classes Hospitalares para o atendimento às crianças e adolescentes durante a internação, como previsto na legislação (BRASIL, 2002). 
para se compreender o que é a deficiência, não basta olhar para aquele que é considerado deficiente, buscando no seu organismo ou no comportamento atributos ou propriedades que possam ser identificados como sendo a própria deficiência ou algum correlato dela. Precisa olhar para o contexto no qual, com seu sistema de crenças e valores e com a dinâmica própria de negociação, alguém é identificado e tratado como deficiente. Tal contexto condiciona o modo de tratamento da pessoa deficiente e por este é condicionado. (OMOTE, 1996, p.133)

JFER, durante as intervenções, deixou claro que sua dificuldade escolar girava em torno de um diagnóstico. E, firmada nessa prerrogativa, desistiu de lutar contra essa barreira imposta de maneira a resistir as ações pedagógicas oferecidas para seu desenvolvimento escolar. Sentiu-se ainda mais incapaz ao ser indicada para uma escola especial para crianças com dificuldade de aprendizagem. Quando a progenitora $\mathrm{M}$ foi interrogada sobre o assunto, disse que a indicação teria sido feita por alguém dentro do hospital e não se lembrava o nome.

Não sei, foi alguém aqui do hospital, agora não lembro quem, mas foi aqui no hospital. (...) Eles trabalham oficina, eles fazia oficina para preparar eles para o campo de trabalho, futuro se ela for trabalhar e alfabetizar. Alfabetizar para eles saber assinar o nome. (...)É, mais assim, a professora falou que era para eu ver se conseguia uma vaga na escola especial, para desenvolver para isso a escola especial trabalha essas partes de atenção, tudo. $\mathrm{Na}$ escola normal igual ela tá não vai desenvolver isso. (M)

Em relação ao encaminhamento, foi questionado se foi realizado na presença de JFER. O fato é que, quando JFER, interrogada sobre esses locais de aprendizagem diferenciados, demonstrou notória irritação e semblante entristecido. A progenitora M relata que

(...) conheço a escola especial de filhos de amigas minhas estudando. Hoje, se eu tivesse a cabeça que eu tenho a JFER era alfabetizada, porque eu não coloquei a JFER na escola especial por influência do meu ex-marido, ele falava que ela não era louca para ir para a escola especial, e hoje o (...), esse menino que está aqui ó (aponta para menino ao lado), ele estudou na escola especial. Ele lê, ele escreve, teve a mesma doença da JFER. (M)

As entrevistas e os registros dos atendimentos pedagógico-escolares desvelaram que a escola regular não promoveu ações que estimulassem a superação das dificuldades existentes, despertando na criança o desejo de permanência na escola, promovendo a evasão escolar e dando um significado negativo às atividades que envolviam leitura e escrita. Sobre a escola regular, $\mathrm{M}$ afirma:

Não, não ensina. Infelizmente deixa a desejar prás crianças que tem algum tipo de deficiência. (M)

Analisando a trajetória escolar de JFER, pode-se considerar que, por vezes, o direito ao ingresso na escola no ensino regular, garantido pela legislação brasileira, nem sempre foi respeitado, com alegação de falta de estrutura física adequada, despreparo por parte de gestores, professores e funcionários, podendo, assim, estar contribuindo significativamente como processo de exclusão, pois ela vivenciou o não pertencimento ao ambiente escolar. Essa rejeição se estende aos responsáveis dessas crianças que, buscando a proteção de seus filhos, se distanciam da requisição de direitos à escolarização de suas crianças com necessidades educacionais específicas.

Na rotina de JFER é obrigatório e indispensável o seu comparecimento ao setor de nefrologia do Hospital, para a realização de hemodiálise, intermitentemente três vezes semanais, no período matutino, compreendido das 7 às 11 horas, ou seja, são quatro horas ligada à máquina de hemodiálise. Frequentemente, os períodos e horários se estendem devido às consultas médicas, assistência psicológica, consultas odontológicas, exames laboratoriais, ultrassonografias e orientações nutricionais, estando, ainda, propensa a infecções recorrentes, as internações de JFER não são raras, podendo assim dificultar sua trajetória escolar. Assim, na trajetória de JFER, não foi possível verificar o estabelecimento de fontes de apoio externo, em relação à doença e à escolarização, dificultando a continuidade do seu processo educativo (SCHWARTZ et al., 2009, p. 194), 
É notório que o tratamento da doença impõe modificações significativas no cotidiano de crianças que possuem doenças crônicas, imprimindo limitações, como foi observado no caso estudado. Nóbrega et al. (2010) e Albertoni (2014) afırmam, ainda, que os entendimentos e as crenças sobre a doença podem determinar interferências e singularidades no processo de escolarização do aluno com doença crônica.

Contudo, a partir dos atendimentos pedagógico-escolares do GEPPH, junto às crianças e adolescentes do setor de Hemodiálise, desde o ano de 2014, foi possível perceber que JFER foi apresentando respostas mais positivas frente à oferta de atividades escolares no hospital. Como exemplo, podemos citar o contato com o projeto de conhecer pintores e reproduzir suas obras. Sobre isso, JFER relata:

Não acredito! Meu sonho está se realizando. (JFER)

Outra situação vivenciada que desvela a mudança de JFER frente ao seu processo de escolarização foi demonstrado, quando ela relata estar feliz por frequentar a escola normalmente sem faltar às aulas. Relata também que gostou do livro Encontro com Portinari - Rosane Acedo / Cecília Aranha - da coleção Encontro com a arte Brasileira, ressaltando que

Estou ansiosa para começar a pintar. (JFER)

Foi com esse projeto que JFER aprendeu a assinar o seu nome, pois surgiu a necessidade de ela garantir a autoria de suas obras. Dessa forma, o atendimento pedagógico-escolar realizado teve grande contribuição para o processo de escolarização e aprendizagem e, com isso, o espaço-tempo da hemodiálise pode ser ressignificado, pois compreendeu-se os processos de desenvolvimento da adolescente de forma global com foco na vida para além da doença e do tratamento (TINÓS, et al, 2017).

Assim, compreendendo a trajetória escolar de JFER, pode-se pensar que os serviços educacionais vivenciados não apresentaram a qualidade presumidamente prevista na legislação, pontuando a falta de interlocução entre a escola, a família e a equipe médica. Em contrapartida, essa trajetória também desvelou a importância do oferecimento de serviços educacionais em ambientes hospitalares, que foi ofertado em um projeto de pesquisa fundamental para o resgate do processo de escolarização JNER.

\section{CONSIDERAÇÕES FINAIS}

Ao compreender a trajetória escolar de uma adolescente com mielomeningocele e insuficiência renal crônica, buscou-se delinear os percursos escolares na escola e no hospital, tendo como resultados a necessidade de se pensar em possibilidades de intervenção pedagógica nos hospitais e nas escolas regulares, considerando a problemática que envolve a doença crônica na infância e os seus impactos na escolarização.

A realização desta pesquisa permitiu identificar necessidades educacionais específicas da adolescente com mielomeningocele e insuficiência renal crônica frente às subjetividades e complexidades que se formam ao redor do fazer pedagógico dentro de uma unidade hospitalar, em um centro de hemodiálise. As condições objetivas da doença crônica configuraram, desde o nascimento, deficiências que foram diagnosticadas e construídas, pela equipe de saúde, mãe e adolescente, ao longo de seu percurso escolar, evidenciando dificuldades e entraves nesse processo. Por outro lado, o olhar durante os atendimentos pedagógico-escolares descortinou novos caminhos que poderiam descontruir a autoimagem da deficiência e da incapacidade de aprender. 
Assim, este estudo conduz à compreensão de que as trajetórias escolares de crianças e adolescentes com doenças crônicas podem apresentar problematizações muito semelhantes em termos de diagnósticos e percursos escolares, mas o entendimento da doença e seu tratamento não são determinantes dos processos de aprendizagem e escolarização. Nesse sentido, destaca-se a importância dos atendimentos pedagógico-escolares junto à adolescente durante as sessões de hemodiálise, visando ao despertar de interesse pela educação escolar e sua alfabetização, em contrapartida ao fato de se apresentar atraso na escolarização. Os atendimentos pedagógico-escolares trouxeram à tona as dificuldades, mas também as possibilidades de aprendizagem da adolescente, focando suas potencialidades de aprender e não sua fragilidade na execução das atividades pedagógicas oferecidas. Houve planejamento cuidadoso na preparação das atividades pedagógicas, sintonizado com suas necessidades educacionais específicas e nas suas potencialidades de aprendizagem.

É importante salientar que esse avanço em sua trajetória escolar foi possível a partir de um olhar e uma escuta atentiva para o interesse da adolescente pelas artes, principalmente pela pintura a óleo sobre tela. Foi o recurso material que possibilitou o despertar da aprendizagem e o retorno à sala de aula regular, pois a possibilidade de apresentar aos colegas escolares sua aptidão em pintar de quadros despertou sua autoestima e se desconstruiu uma imagem de deficiência e incapacidade.

Assim, podemos inferir que a doença crônica e seu tratamento não inviabiliza a vida escolar das crianças e adolescentes, desde que haja as condições educacionais necessárias para criar elos entre o hospital e a escolarização. Dentre essas condições, destaca-se a atuação pedagógica dentro do ambiente hospitalar, seja em situações de internação ou semi-internação, como é o caso de centros de hemodiálise. Atendimentos pedagógico-escolares frequentes que buscam compreender a trajetória escolar de crianças e adolescentes contribuem para se pensar em ações e estratégias e tornar a escolarização desse público possível. Assim, esses atendimentos configuram-se como serviços educacionais-hospitalares relevantes na vida escolar de crianças e adolescentes com doenças crônicas.

Por fim, considerando a premissa do direito à Educação para todos e os aspectos ligados à implementação efetiva das políticas educativas nos hospitais, ressalta-se a necessidade de mais pesquisas que traduzam a realidade brasileira sobre a trajetória escolar de crianças e adolescentes com doenças crônicas. Dados objetivos de percursos escolares, assim como o apresentado neste estudo, podem contribuir para se pensar em possibilidades de atuação pedagógica em hospitais e a configuração de serviços educacionais, estratégias e recursos materiais, em espaços antes pensados apenas para tratamento de saúde.

\section{REFERÊNCIAS}

ALBERTONI, C, L. A inclusão escolar de alunos com doenças crônicas: professores e gestores dizem que... 1.ed. Curitiba: Appris, 2014. 112 p.

AMARAL, A, L. Pensar a diferença/deficiência. 1. ed. CORDE: São Paulo, 1994. 91 p.

ARAÚJJ, C. C. A. C. A. Atendimento Escolar em ambiente hospitalar: Um estudo de caso do estado de São Paulo. 2017. 337 p. Dissertação (Mestrado em Administração Pública)- Escola de Governo Professor Paulo Neves de Carvalho, Fundação João Pinheiro, Belo Horizonte, 2017.

ASSIS, W. Classe hospitalar: um olhar pedagógico singular. 1. ed. São Paulo: Phorte, 2009. 184 p. 
BEVILACQUA, et al. Cirurgia fetal endoscópica para correção de mielomeningocele: passado, presente e futuro. Einstein, São Paulo, v. 13, n. 2, p. 283-289, mar. 2015.

BIANCHETTI, L.. Um olhar sobre a diferença: as múltiplas maneiras de olhar e ser olhado e suas decorrências. Revista Brasileira de Educação Especial, Marília, v. 8, n. 1, p. 1-8, abr. 2018.

BIZZI, J. W. J. MACHADO. A. Mielomeningocele: conceitos básicos e avanços recentes. Jornal Brasileiro de Neurocirurgia, Rio de Janeiro, v. 23, n. 2, p. 138-151, mar./ago. 2018. Disponívelem:<http://bases.bireme.br/cgibin/wxislind.exe/iah/online/?IsisScript=iah/iah. $x i s \& s r c=$ google $\&$ base $=$ LILACS\&lang $=p \&$ nextAction $=\operatorname{lnk\& exprSearch}=655804 \&$ indexSearch $=\mid D>$. Acesso em: 20 set. 2017.

BRASIL. Constituição da República Federativa do Brasil, de 05 de outubro de 1988. Brasília, Senado Federal: Centro Gráfico, 1988. Disponível em: <http://portal.mec.gov.br/secretaria-de-educacao-especialsp-598129159/legislacao >. Acesso em: 17 maio 2017.

Lei n. 8.069, de 13 de julho de 1990. Dispõe sobre o Estatuto da Criança e do Adolescente, e dá outras providências. Brasília, 1990. Disponível em; <http://portal.mec.gov.br/secretaria-de-educacaoespecial-sp-598129159/legislacao>. Acesso em: 17 maio 2017.

Política Nacional de Educação Especial. Brasília: Ministério da Educação e do Desporto. Secretaria de Educação Especial - MEC/SEESP, 1994. Disponível em; <http://portal.mec.gov.br/secretaria-deeducacao-especial-sp-598129159/legislacao >. Acesso em: 17 maio 2017.

Lei n. ${ }^{\circ}$ 9394, de 20 de dezembro de 1996. Lei de Diretrizes e Bases da Educação Nacional. Brasília: Imprensa Oficial, 1996. Disponível em <http://portal.mec.gov.br/secretaria-de-educacaoespecial-sp-598129159/legislacao >. Acesso em: 01 jun. 2017.

Plano Nacional de Educação. Brasília, 1997. Disponível em acesso em: 17 de maio de 2018. Disponível em: <http://portal.mec.gov.br/arquivos/pdf/pne.pdf $>$. Acesso em: 10 maio 2017.

Direito à educação necessidades educacionais especiais: subsídios para a atuação do ministério público brasileiro. Brasília: MEC/SEESP, 2001. Disponível em <http://portal.mec.gov.br/secretaria-deeducacao-especial-sp-598129159/legislacao>. Acesso em: 17 maio 2018.

Diretrizes Curriculares Nacionais para a Formação de Professores da Educação Básica, em nível superior, Curso de Licenciatura, de graduação plena. Brasília, 2002. Disponível em <http://portal.mec. gov.br/secretaria-de-educacao-especial-sp-598129159/legislacao >. Acesso em: 08 maio 2017.

Documento subsidiário à política de inclusão. Brasília: MEC, 2005. Disponível em: <http://portal. mec.gov.br/secretaria-de-educacao-especial-sp-598129159/legislacao. Acesso em: 17 maio 2017.

Documento de diretrizes para o cuidado das pessoas com doenças crônicas nas Redes de Atenção

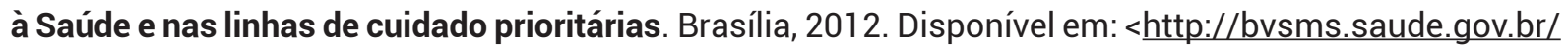
bvs/publicacoes/diretrizes\%20_cuidado_pessoas\%20_doencas_cronicas.pdf $>$. Acesso em: 24 jun. 2016.

FERNANDES, C. A. Malformações do tubo neural. In: Hebert, S. et al. Ortopedia e traumatologia: princípios e prática. 1. ed. Porto Alegre: Artmed, 2003. 839-857 p.

FONSECA, E. S.. Atendimento escolar no ambiente hospitalar. 2. ed. São Paulo: Memnon, 2003. 100 p. 
JUCA, C. E. B. Tratamento de hidrocefalia com derivação ventrículo-peritoneal: análise de 150 casos consecutivos no hospital das clínicas de Ribeirão Preto. Acta Cirurgica Brasileira, São Paulo, v. 17, abr./ago. 2018. Disponível em: <http://dx.doi.org/10.1590/S0102-86502002000900013. >. Acesso em: 20 set. 2017.

MARTINS, J.; BICUDO, M. A. V. A pesquisa qualitativa em psicologia: fundamentos e recursos básicos. 5. ed. São Paulo: Centauros, 2005. 110 p.

MAZER-GONÇALVES, S. M. Construção de uma proposta de formação continuada para professores de classe hospitalar. 2013. 186 p. Tese (Doutorado em Educação Especial)- Programa de Pós-Graduação em Educação Especial, Universidade Federal de São Carlos, São Carlos, 2013.

NOBREGA, R. D. et al. Criança em idade escolar hospitalizada: significado da condição crônica. Texto Contexto Enfermagem, Florianópolis, v. 1, n. 19, p. 425-433, jul. 2010.

RODRIGUES, D. Inclusão e Educação: doze olhares sobre a educação inclusiva. 1. ed. São Paulo: Summus, 2006. $318 \mathrm{p}$.

SCHWARTZ, E. et al. As redes de apoio no enfrentamento da doença renal crônica. Revista Mineira de Enfermagem, Belo Horizente, v. 13, n. 2, p. 193-201, abr. 2009. Disponível em: <http://www.reme.org. br/content/imagebank/pdf/v13n2a05.pdf>. Acesso em: 8 maio 2017.

SILVA, P. B. G. Educação e Identidade dos Negros Trabalhadores Rurais de Limoeiro. 1987. 293 p. Tese (Doutorado em Educação) Programa de Pós-Graduação em Educação. Universidade Federal do Rio Grande do Sul. Porto Alegre, 1987.

TINÓS, L.M.S. Caminhos de alunos com deficiências à educação de jovens e adultos: conhecendo e compreendendo trajetórias escolares. 2010.125 p. Tese (Doutorado em Educação Especial) - Universidade de São Carlos, São Carlos, SP, 2010.

TINÓS, L. M. S. et al. Atendimento Pedagógico-Educacional no Setor de Hemodiálise Infantil: a Construção de um Serviço Educacional Hospitalar. Educação em Revista, Marília, v. 18, n. 2, p. 91-104, jul. 2017. UNESCO. Declaração de Salamanca e Linha de Ação sobre Necessidades Educacionais Especiais. Salamanca, 1994.

YUNGE, D. P. Manejo urologico en el niño con disrafia espinal. Rev. Chilena de Neurocirurgia. Chile, 1987 v 1, n 3, p. 223-230, dez. 1997. 